\title{
A bovine hemoglobin-based oxygen carrier as pump prime for cardiopulmonary bypass: Reduced systemic lactic acidosis and improved cerebral oxygen metabolism during low flow in a porcine model
}

\author{
Jeffrey D. McNeil, MD, ${ }^{\mathrm{a}, \mathrm{c}}$ Brandon Propper, MD, ${ }^{\mathrm{c}}$ Joshua Walker, CPP, ${ }^{\mathrm{a}}$ Lauren Holguin, BS, ${ }^{\mathrm{a}}$ \\ Lauren Evans, BS, ${ }^{\mathrm{a}}$ Kihak Lee, PhD, ${ }^{\mathrm{b}}$ Peter T. Fox, MD, ${ }^{\mathrm{b}}$ Joel E. Michalek, PhD, ${ }^{\mathrm{d}}$ and \\ Clinton E. Baisden, MD
}

\begin{abstract}
Objectives: Cerebral ischemia can occur during cardiopulmonary bypass, especially during low flow. HBOC201 (OPK Biotech, Cambridge, Mass) is a hemoglobin-based oxygen-carrying solution that enhances oxygen delivery. This project evaluated the benefits on total body and cerebral oxygen delivery and consumption using HBOC-201 during cardiopulmonary bypass.
\end{abstract}

\begin{abstract}
Methods: Twelve immature swine were assigned to one of 2 groups. One group used HBOC-201 in pump prime, and the other used donor porcine blood. Cardiopulmonary bypass was initiated and then flow was serially decreased from $100 \%$ to $75 \%$, to $50 \%$, and then back to full flow. At each interval, ${ }^{15} \mathrm{O}$ positron emission tomographic analysis was performed, and blood was collected. Total body and cerebral oxygen delivery and consumption were calculated. Statistical analysis was performed with a Tukey-Kramer adjusted $P$ value based on a repeated measures linear model on log-transformed data.
\end{abstract}

\begin{abstract}
Results: Total and plasma hemoglobin levels were higher in the HBOC-201 group. Oxygen delivery and consumption were not statistically different but did tend to be higher in the HBOC-201 group. Mixed venous saturation was lower in the HBOC-201 group but not significant. Mild metabolic acidosis with increased lactate levels developed in the blood group. Mean cerebral blood flow decreased in both groups when total flow was $50 \%$. In the HBOC-201 group cerebral oxygen metabolism was maintained.
\end{abstract}

Conclusions: The addition of HBOC-201 for cardiopulmonary bypass appears to improve oxygen use and minimize anaerobic metabolism. Cerebral oxygen use was preserved in the HBOC-201 group, even during decrease in blood flow. These findings support the reported improved oxygen-unloading properties of HBOC-201 and might provide a benefit during cardiopulmonary bypass. (J Thorac Cardiovasc Surg 2011;142:411-7)

HBOC-201 (OPK Biotech, Cambridge, Mass) is a bovine hemoglobin-based oxygen carrier (HBOC). Developed as red cell replacement, these fluids are being evaluated as oxygen therapeutics. HBOCs have characteristics that are beneficial during tissue ischemia. Hemoglobin in solution

\footnotetext{
From the Department of Surgery, ${ }^{a}$ the Research Imaging Institute, ${ }^{b}$ and the Department of Epidemiology and Biostatistics, ${ }^{d}$ University of Texas Health Science Center at San Antonio, San Antonio, Tex; and the Wilford Hall Medical Center, ${ }^{\mathrm{c}}$ 59th Surgical Subspecialties Squadron, Lackland AFB, Tex.

This study was funded by United States Air Force, Office of the Surgeon General, Medical Modernization Directorate, protocol FWH20060196AR. Salary support for student summer research projects was provided by University of Texas Health Science Center, Medical Dean's Office.

The opinions expressed in this paper are solely those of the authors and do not represent the views of the United States Air Force, United States Department of Defense, or the United States Government.

Disclosures: Authors have nothing to disclose with regard to commercial support.

Received for publication July 10, 2010; revisions received Oct 19, 2010; accepted for publication Nov 5, 2010; available ahead of print June 6, 2011

Address for reprints: Lt Col Jeffrey D. McNeil, MD, UTHSCSA, Division of Cardiothoracic Surgery, 7703 Floyd Curl Dr, Mail Code 7841, San Antonio, TX 78229 (E-mail: mcneil@uthscsa.edu).

0022-5223/\$0.00

Published by Elsevier Inc. on behalf of The American Association for Thoracic Surgery

doi:10.1016/j.jtcvs.2010.11.017
}

increases the oxygen-carrying capacity of the plasma phase, decreases the oxygen diffusion resistance, and facilitates oxygen delivery to tissue beds. ${ }^{1,2}$ HBOC-201 is a high $\mathrm{P}_{50}$ (pressure of oxygen that causes the hemoglobin to be $50 \%$ saturated) HBOC: the $\mathrm{P}_{50}$ of HBOC-201 is $38 \mathrm{~mm}$ $\mathrm{Hg}$ compared with $27 \mathrm{~mm} \mathrm{Hg}$ for human intraerythrocytic hemoglobin (Table 1). This decreased affinity enhances oxygen offloading to tissues. ${ }^{3-5}$

Prior work $^{6-9}$ with a porcine model of controlled hemorrhagic shock demonstrated the potential benefits of the enhanced tissue oxygenation. In acute and survival models resuscitation with HBOC-201 led to anaerobic metabolism reversal despite dramatically lower cardiac output, mean arterial pressure, and mixed venous saturation without significant end-organ injury. In these studies, despite lower oxygen delivery and systemic hypotension, oxygen use was maintained, and end-organ function was preserved.

${ }^{15} \mathrm{O}$ positron emission tomography (PET) measures cerebral blood flow (CBF) and cerebral oxygen metabolism $\left(\mathrm{CMRO}_{2}\right)$ and has become the gold standard ${ }^{10,11}$ for cerebral perfusion studies. No studies with ${ }^{15} \mathrm{O}$ PET imaging during cardiopulmonary bypass (CPB) have been 


$$
\begin{aligned}
& \text { Abbreviations and Acronyms } \\
& \begin{aligned}
\mathrm{CaO}_{2} & =\text { arterial oxygen content } \\
\mathrm{CBF} & =\text { cerebral blood flow } \\
\mathrm{CK} & =\text { creatine kinase } \\
\mathrm{CMRO} & =\text { cerebral oxygen metabolism } \\
\mathrm{CPB} & =\text { cardiopulmonary bypass } \\
\mathrm{DO}_{2} & =\text { oxygen delivery } \\
\mathrm{HBOC} & =\text { hemoglobin-based oxygen carrier } \\
\mathrm{P}_{50} & =\text { pressure of oxygen that causes the } \\
& \text { hemoglobin to be } 50 \% \text { saturated } \\
\mathrm{PET} & =\text { positron emission tomography } \\
\mathrm{TNF}-\alpha & =\text { tumor necrosis factor } \alpha \\
\mathrm{VO}_{2} & =\text { oxygen consumption }
\end{aligned}
\end{aligned}
$$

published, but ${ }^{15} \mathrm{O}$ PET has been used to evaluate cerebral metabolism in a porcine model after cardiac arrest. ${ }^{12}$ For brain imaging, major advantages of PET with ${ }^{15} \mathrm{O}$ (halflife, 122.2 seconds) are that the images are rapidly acquired, fully quantitative, and can be repeated every 10 minutes. A limitation of using ${ }^{15} \mathrm{O}$ is that an on-site cyclotron is required to generate the required oxygen radiotracers. Few medical research facilities have the required equipment, precluding widespread application.

Neurologic complications can occur after operations requiring CPB. The common pathway is cerebral ischemia leading to neuronal death. Because of the facilitated oxygen delivery and reduced tissue ischemia during low flow, we hypothesized that HBOC-201 during CPB might improve cerebral protection by minimizing overall end-organ ischemia. No prior investigations have evaluated this hypothesis. However, other clinical situations with end-organ ischemia have been evaluated. In myocardial infarction models prophylactic and therapeutic treatment with HBOC-201 led to significant infarct size reduction. ${ }^{13,14}$ Porcine models of hemorrhagic shock combined with traumatic brain injury ${ }^{15,16}$ with HBOC-201 for resuscitation demonstrated rapidly restored hemodynamics and improved brain tissue oxygenation. A canine model of isovolemic hemodilution found that tissue oxygenation in both skeletal muscle and liver parenchyma was increased to greater than baseline values ${ }^{17}$ in the HBOC-201 group. Therefore we measured $\mathrm{CBF}$ and $\mathrm{CMRO}_{2}$ values in a porcine model of normothermic low-flow CPB.

\section{MATERIALS AND METHODS Animal Model}

This study was reviewed and approved by the Wilford Hall Medical Center Animal Care and Use Committee. All animals were cared for according to the "Guide for the care and use of laboratory animals." ${ }^{18}$ Twelve Yorkshire swine (weight, $23.3 \pm 3.3 \mathrm{~kg}$ ) were randomized to one of 2 groups. Animals were fasted but had access to water. Animals were premedicated with intramuscular ketamine $(15-20 \mathrm{mg} / \mathrm{kg})$ and atropine $(0.04-0.4 \mathrm{mg} / \mathrm{kg})$. Intravenous access was established. Mask induction with isoflurane $(2.0 \%-4.0 \%)$ in $100 \%$ oxygen was performed, followed by endotracheal intubation. Anesthesia was maintained with isoflurane $(0.25 \%-2.0 \%)$ in $100 \%$ oxygen, and the animals were mechanically ventilated with a positive end-expiratory pressure of $3 \mathrm{~cm} \mathrm{H}_{2} \mathrm{O}$. Femoral intravascular catheters were placed by means of a cutdown procedure. Median sternotomy and systemic heparinization (300-500 U/kg administered intravenously) were performed. The activated coagulation time was maintained at greater than 450 seconds. A venous cannula was placed through the right atrial appendage. An arterial cannula was placed in the ascending aorta. The left atrium was vented through the appendage. The aortic arch was mobilized, and the ligamentum arteriosum was ligated. A fiberoptic positron $\left(\beta^{+}\right)$probe was placed in the right brachiocephalic artery and advanced into the right common carotid artery.

The animals were transferred from the surgical suite to the PET scanner, and the cannulae were connected to the bypass circuit. Positioning for PET scanning was accomplished, baseline measurements were recorded, and blood samples were collected. Before initiating CPB, additional anesthetic with fentanyl (30-100 $\left.\mu \mathrm{g} \cdot \mathrm{kg}^{-1} \cdot \mathrm{h}^{-1}\right)$ and neuromuscular blockade with pancuronium bromide $(0.02-0.15 \mathrm{mg} / \mathrm{kg}$ administered intravenously) were administered. Isoflurane $(0.25 \%-2.0 \%)$ was continued through a vaporizer on the $\mathrm{CPB}$ circuit.

\section{Experimental Protocol}

In group A HBOC-201 was added to the standard priming solution (12.5 $\mathrm{g}$ of mannitol, $50 \mathrm{mEq}$ of $\mathrm{NaHCO}_{3}$, and 10,000 units of heparin in isotonic saline) to produce a systemic serum concentration of free hemoglobin of $2 \mathrm{~g} / \mathrm{dL}$ by using the following formula:

$$
\text { Vol HBOC }=\frac{\text { desired }[\text { free } H g] \times(E B V+\text { circuit volume })}{[H g] \text { in } H B O C},
$$

where EBV is defined as estimated blood volume $(70 \mathrm{~mL} / \mathrm{kg})$, circuit volume is $800 \mathrm{~mL}$, and hemoglobin $(\mathrm{Hg})$ in $\mathrm{HBOC}$ is $13 \mathrm{~g} / \mathrm{dL}$.

In group B the same prime with a similar volume of donor porcine whole blood was used. Other than this difference in the priming solution, both groups were treated identically. The bypass circuit consisted of an S-3 roller-head bypass system (Sorin Medical, Denver, Colo) with a Capiox RX15 oxygenator, AF125X arterial filter, and HC05 hemoconcentrator (Terumo Medical, Somerset, NJ) using 3/8-inch tubing for arterial and venous lines. Full-flow normothermic CPB $\left(100 \mathrm{~mL} \cdot \mathrm{kg}^{-1} \cdot \mathrm{min}^{-1}\right)$ was initiated and maintained for 30 minutes, and the flow was decreased to $75 \%$ for 30 minutes and $50 \%$ for 30 minutes and then returned to full flow for 30 minutes. Animals were separated from CPB, observed for 30 minutes, and then killed. Cardioplegic arrest was not performed. Vacuum-assisted venous drainage and venting of the left atrium were performed to optimize venous drainage and ensure that no ventricular ejection contributed to cardiac output. Hemodynamic support with dopamine infusion was used as necessary. Heparinization was not reversed, and cannulae were left in place throughout all data acquisition. At each interval, ${ }^{15} \mathrm{O}$ PET imaging was performed, and arterial and venous blood samples were collected. Arterial blood pressure was monitored continuously through the femoral arterial line, and heart rate was monitored by means of continuous electrocardiographic analysis. Core temperature was measured by using a rectal temperature probe. CPB flow was measured with an ultrasonic flow probe on the arterial inflow tubing and recorded at each interval.

${ }^{15} \mathrm{O}$ tomographic analysis was performed on a research-dedicated Siemens/CTI HR+ scanner (Siemens/CTI, Knoxville, Tenn) in 2-dimensional acquisition mode to reduce scattered-photon counts. For calibration, a blank scan was performed before the animals were placed on the scanner. For each animal, a 10-minute transmission scan was done with a rotating rod source of ${ }^{68} \mathrm{Ge}$ to correct the subsequent emission scans. For CBF measurement, $1480 \mathrm{MBq}$ of $\mathrm{H}_{2}{ }^{15} \mathrm{O}$ in $6 \mathrm{~mL}$ of saline was injected as an intravenous bolus beginning 20 seconds before scan initiation. $\mathrm{CMRO}_{2}$ was measured by using $4810 \mathrm{MBq}$ of ${ }^{15} \mathrm{O}_{2}$ in a 2-L air bag delivered across the $\mathrm{CPB}$ oxygenator membrane. Arterial input function was measured with a $\beta^{+}$probe system 
TABLE 1. Properties of HBOC-201

$13 \mathrm{~g} / \mathrm{dL}$ polymerized hemoglobin
$<5 \%$ as unstabilized tetramers
Approximately $50 \%$ between 65 and $130 \mathrm{kd}$
$\quad<10 \%$ are $>500 \mathrm{kd}$
Colloid oncotic pressure: $18 \mathrm{~mm} \mathrm{Hg}$
Half-life: $24-30 \mathrm{~h}$
$\mathrm{pH} 7.8$
$\mathrm{KCl}: 4 \mathrm{mmol} / \mathrm{L}$
$\mathrm{NaOH}: 10 \mathrm{mmol} / \mathrm{L}$
$\mathrm{P}_{50}: 38 \mathrm{~mm} \mathrm{Hg}$
$300 \mathrm{mOsm} / \mathrm{kg}$
$\mathrm{NaCl}: 113 \mathrm{mmol} / \mathrm{L}$
$\mathrm{CaCl} 2: 1.4 \mathrm{mmol} / \mathrm{L}$
$\mathrm{Sodium}$ lactate: $27 \mathrm{mmol} / \mathrm{L}$
$\mathrm{N}$-acetyl-L-cysteine: $200 \mathrm{mg} / \mathrm{dL}$
$<0.1 \mu \mathrm{g} / \mathrm{mL}$ free glutaraldehyde
$<0.05 \mathrm{EU} / \mathrm{mL}$ endotoxin
$P_{50}$, Pressure of oxygen that causes the hemoglobin to be $50 \%$ saturated.

$P_{50}$, Pressure of oxygen that causes the hemoglobin to be $50 \%$ saturated.

developed by Lee and colleagues. ${ }^{19}$ The intra-arterial $\beta^{+}$probe was placed into the common carotid artery, and a second probe was placed outside the body to remove background gamma radiation. PET images were reconstructed with a standard, filtered back-projection algorithm with a 5-mm FWHM Hann filter. Decay and dead time corrections were done during image reconstruction. The images were coregistered by anatomic magnetic resonance images. Absolute whole-brain CBF (in milliliters per $100 \mathrm{~g}$ per minute) and $\mathrm{CMRO}_{2}$ (in milliliters per $100 \mathrm{~g}$ per minute) were calculated by using the Ohta method for different bypass stages. The cerebral oxygen extraction fraction $(\mathrm{OEF})$ was estimated from the relationship between $\mathrm{CBF}$ and $\mathrm{CMRO}_{2}\left(\mathrm{ie}, \mathrm{CMRO}_{2}=\mathrm{CBF} \times \mathrm{OEF} \times\right.$ oxygen content). ${ }^{20}$

At each interval, arterial and mixed venous blood was collected and analyzed with an on-site Radiometer ABL 510 (Copenhagen, Denmark) for standard blood gas values, hemoglobin, co-oximetry, and lactate levels. By using these data, the arterial and venous oxygen content was calculated. Oxygen delivery, oxygen consumption, and the oxygen extraction ratio were calculated at each bypass flow rate. At baseline and after separation from CPB, blood was collected and stored for subsequent analysis. Complete cell counting was performed on an ADVIA analyzer (Siemens Healthcare, Deer Park, Ill) after completion of each experiment. Standard serum chemistries were performed with a Vetscan analyzer (Abaxis, Union City, Calif). Baseline and completion serum samples were analyzed on a Radiometer ABL 510 for the concentration of cell-free hemoglobin. Specimens for inflammatory mediators (tumor necrosis factor $\alpha$ [TNF- $\alpha]$ and interleukin 6) were collected, stored at $-78^{\circ} \mathrm{C}$, and subsequently analyzed in batches by using ELISA kits (R\&D Systems, Minneapolis, Minn). Similarly, troponin (Life Diagnostics, West Chester, Pa) and creatine kinase (CK) MB (Diagnostic Automation, Calabasas, Calif) levels were determined by using ELISA kits on stored specimens in batches.

Data were summarized with the mean \pm 1 standard deviation in original units. Mean contrasts were carried out with a Tukey-Kramer adjusted $P$ value based on a repeated-measures linear model on log-transformed data with a compound symmetric covariance assumption. All statistical testing was 2-sided, with an experiment-wise significance level of $5 \%$. SAS Version 9.2 for Windows software (SAS Institute, Inc, Cary, NC) was used throughout.

\section{RESULTS}

All animals survived to completion of the protocol, with the exception of 1 animal that was excluded because of loss of airway with hemodynamic compromise. During transfer, this animal became extubated, leading to significant hypoxia and hypercarbia with subsequent hemodynamic compromise. The data from this animal were discarded, and the animal was not replaced. One animal had acute hindlimb ischemia caused by arterial thrombosis at the femoral artery catheter site. Hemodynamic and PET data were used from this animal, but metabolic and inflammatory markers that would have been influenced by the extremity ischemia were not included in the data analysis. The mean weights of the animals in both groups were not significantly different. The mean volume of HBOC-201 used for each animal was $372 \pm 24 \mathrm{~mL}$ or $16.2 \pm 0.4 \mathrm{~mL} / \mathrm{kg}$.

\section{Hemodynamics}

In the HBOC group the mean arterial pressure was higher and the mean heart rate remained lower (Figure 1). No animals required the use of dopamine during $\mathrm{CPB}$. Three $(60 \%)$ of 5 animals in the HBOC group compared with zero $(0 \%)$ of 6 in the no-HBOC group required transient low-dose dopamine $\left(3-5 \mu \mathrm{g} \cdot \mathrm{kg}^{-1} \cdot \mathrm{min}^{-1}\right)$ to maintain a mean arterial pressure of $55 \mathrm{~mm} \mathrm{Hg}$ or greater in the period immediately after separation from bypass. At baseline, animals were mildly hypothermic, but once bypass was initiated, all animals returned to normothermia. There were no significant differences in core temperatures between the 2 groups.

\section{Global Oxygen Metabolism}

The HBOC group had a significantly higher mean total hemoglobin level at baseline $(9.7 \pm 0.7$ vs $8.5 \pm 0.7 \mathrm{~g} / \mathrm{dL}$, $P=.02$ ), and this persisted throughout the protocol, including after CPB $(9.0 \pm 0.8$ vs $7.6 \pm 0.7 \mathrm{~g} / \mathrm{dL}, P=.005)$. Plasma hemoglobin was nearly undetectable at baseline $(0.1 \pm 0.1 \mathrm{~g} / \mathrm{dL}$ in the HBOC group vs $0.02 \pm 0.04 \mathrm{~g} / \mathrm{dL}$ in the blood group). In the HBOC group the mean plasma hemoglobin level increased to $2.2 \pm 0.3 \mathrm{~g} / \mathrm{dL}(P=.05)$ compared with $0.02 \pm 0.04 \mathrm{~g} / \mathrm{dL}$ in the blood group after CPB.

Mean arterial oxygen content $\left(\mathrm{CaO}_{2}\right)$ was also higher in the HBOC group at baseline and all subsequent time points (Table 2). The mean $\mathrm{CaO}_{2}$ value decreased from baseline in both groups once CPB was initiated because of hemodilution with the priming solution. At each interval, CPB flow changed as intended in the study design and did not vary significantly between groups at each time point. Despite the higher mean $\mathrm{CaO}_{2}$ value in the $\mathrm{HBOC}$ group, calculated mean oxygen delivery $\left(\mathrm{Do}_{2}\right)$ was not significantly different between the 2 groups but did decrease relative to baseline as mean CPB flow decreased. Calculated mean oxygen use $\left(\mathrm{VO}_{2}\right)$ did not vary significantly between groups. At $50 \%$ CPB flow, the decrease in mean $\mathrm{VO}_{2}$ value became significant relative to the baseline value. Mixed venous saturation decreased significantly at the $75 \%$ flow rate in both groups and remained decreased even after full flow had been resumed. 

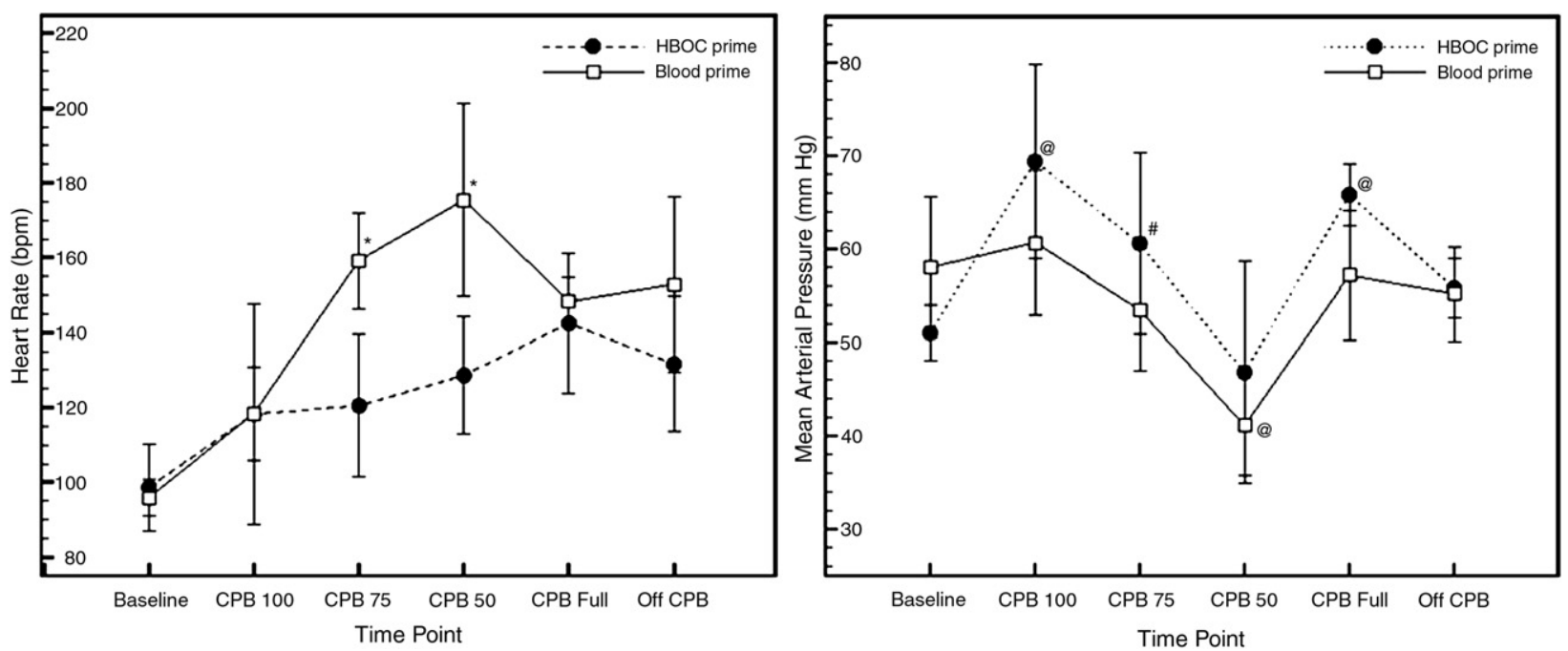

FIGURE 1. Heart rate and mean arterial pressure during cardiopulmonary bypass $(C P B) . * P \leq .001$ between groups, @P $<.001$ compared with baseline, and $\# P=.02$ compared with baseline.

\section{Global Metabolic Markers}

Mean methemoglobin percentages were similar at baseline $(0.7 \% \pm 0.4 \%$ vs $1.3 \% \pm 0.8 \%)$, remained at this level in the blood group, and increased to a peak of $2.3 \%$ $\pm 0.8 \%$ in the HBOC group versus $1.1 \% \pm 0.5 \%$ in the blood group $(P<.001)$. At all time points after initiating bypass, the methemoglobin percentage was significantly higher in the HBOC group. Mild metabolic acidosis developed in the blood group, as reflected by the mean arterial base excess and mean arterial $\mathrm{pH}$ (Table 3 ). In the HBOC-treated group these parameters were not statistically different from baseline. In both groups mean serum lactate levels were normal at baseline and increased as flow rate was decreased, although to a lesser degree in the HBOC group.

\section{${ }^{15}$ O PET}

Mean CBF and mean cerebral metabolic rate of oxygen at $100 \%$ CPB flow was consistent with normal values for the porcine brain. $\mathrm{CBF}$ was maintained at $75 \% \mathrm{CPB}$ flow but decreased significantly from the full-flow state in both groups when total CPB flow was decreased to $50 \%$, with no significant difference between the 2 groups (Table 4). Once full flow was resumed, the values for mean CBF exceeded baseline values. Mean $\mathrm{CMRO}_{2}$ was also maintained at $75 \%$ of CPB flow in both groups. In the blood group the mean $\mathrm{CMRO}_{2}$ value decreased significantly when total flow was reduced to $50 \%$. In the $\mathrm{HBOC}$ group the mean $\mathrm{CMRO}_{2}$ value also decreased, but the decrease did not reach significance $(P=.14)$. The mean brain oxygen extraction fraction increased as total flow, and the change became significant in the HBOC group at $50 \%$ flow.

\section{Inflammatory Markers and Cardiac Enzymes}

Serum levels of inflammatory markers, cardiac enzymes, magnesium, and platelets are summarized in Table 5. Values of all of these, with the exception of magnesium and TNF- $\alpha$, changed significantly from baseline to completion. Mean CK levels were increased at baseline because of the sample being collected after opening of the chest and

TABLE 2. Oxygen delivery and consumption

\begin{tabular}{|c|c|c|c|c|c|c|c|c|}
\hline & \multicolumn{4}{|c|}{ HBOC-201 prime $(n=5)$} & \multicolumn{4}{|c|}{ Blood prime $(n=6)$} \\
\hline & $100 \%$ & $75 \%$ & $\mathbf{5 0} \%$ & $100 \%$ & $100 \%$ & $75 \%$ & $\mathbf{5 0} \%$ & $100 \%$ \\
\hline Total hemoglobin (g/dL) & $9.0 \pm 0.6 \dagger$ & $8.7 \pm 0.7 \dagger$ & $8.9 \pm 1.3 \dagger$ & $8.4 \pm 0.6^{*}$ & $7.4 \pm 0.4^{*}, \ddagger$ & $7.4 \pm 0.8^{*}, \ddagger$ & $7.4 \pm 0.8^{*}, \ddagger$ & $7.2 \pm 0.7^{*}, \ddagger$ \\
\hline CPB flow (L/min) & $2.3 \pm 0.2$ & $1.7 \pm 0.1^{*}$ & $1.2 \pm 0.1^{*}$ & $2.3 \pm 0.2$ & $2.4 \pm 0.5$ & $1.8 \pm 0.3^{*}$ & $1.2 \pm 0.2^{*}$ & $2.4 \pm 0.4$ \\
\hline $\mathrm{CaO}_{2}\left(\mathrm{~mL} \mathrm{O}_{2} / \mathrm{dL}\right)$ & $12.8 \pm 0.6 \dagger$ & $12.3 \pm 0.9^{*}$ & $12.9 \pm 1.6 \dagger$ & $11.8 \pm 0.7 *$ & $10.9 \pm 0.5^{*}, \ddagger$ & $10.9 \pm 1.3^{*}, \ddagger$ & $10.9 \pm 1.3^{*}, \ddagger$ & $10.4 \pm 1.2 *, \ddagger$ \\
\hline $\mathrm{SvO}_{2}(\%)$ & $61.5 \pm 7.2$ & $44.1 \pm 7.3^{*}$ & $36.8 \pm 6.4^{*}$ & $53.0 \pm 6.3 \dagger$ & $65.4 \pm 8.2$ & $51.2 \pm 9.7^{*}$ & $37.9 \pm 9.5^{*}$ & $57.6 \pm 10.1 \dagger$ \\
\hline $\mathrm{Do}_{2}\left(\mathrm{~mL} \mathrm{O}_{2} / \mathrm{min}\right)$ & $293 \pm 28$ & $211 \pm 29 *$ & $150 \pm 29 *$ & $271 \pm 30 \dagger$ & $257 \pm 57$ & $190 \pm 34 *$ & $129 \pm 26^{*}$ & $246 \pm 58$ \\
\hline $\mathrm{VO}_{2}\left(\mathrm{~mL} \mathrm{O}_{2} / \mathrm{min}\right)$ & $122 \pm 26$ & $122 \pm 21$ & $99 \pm 22 *$ & $134 \pm 27$ & $105 \pm 38$ & $95 \pm 18$ & $86 \pm 28^{*}$ & $112 \pm 29$ \\
\hline
\end{tabular}

$\mathrm{CPB}$, Cardiopulmonary bypass; $\mathrm{CaO}_{2}$, arterial oxygen content; $\mathrm{Svo}_{2}$, mixed venous oxygen saturation; $\mathrm{Do}_{2}$, oxygen delivery; $\mathrm{Vo}_{2}$, oxygen consumption. $* \mathrm{P} \leq .001$ relative to initial full flow (100\%), within group. $\dagger P<.05$ relative to initial full flow (100\%), within group. $\ddagger P<.05$, between groups. 
TABLE 3. Acid/base measurements

\begin{tabular}{|c|c|c|c|c|c|c|c|c|c|c|c|c|}
\hline & \multicolumn{6}{|c|}{ HBOC-201 prime $(n=4)$} & \multicolumn{6}{|c|}{ Blood prime $(n=6)$} \\
\hline & Baseline & $100 \%$ & $75 \%$ & $\mathbf{5 0} \%$ & $100 \%$ & Off CPB & Baseline & $100 \%$ & $75 \%$ & $\mathbf{5 0} \%$ & $100 \%$ & Off CPB \\
\hline $\mathrm{BE}(\mathrm{mEq} / \mathrm{L})$ & $6.0 \pm 4.1$ & $6.4 \pm 3.1$ & $7.0 \pm 4.1$ & $3.9 \pm 3.4$ & $5.5 \pm 2.7$ & $4.1 \pm 3.9$ & $5.6 \pm 3.4$ & $7.6 \pm 3.3 \dagger$ & $6.4 \pm 3.5$ & $2.0 \pm 3.2 \dagger$ & $2.6 \pm 4.1$ & $4.2 \pm 4.3$ \\
\hline $\mathrm{pH}$ & $7.44 \pm 0.08$ & $7.45 \pm 0.09$ & $7.48 \pm 0.07$ & $7.47 \pm 0.07$ & $7.44 \pm 0.06$ & $7.43 \pm 0.06$ & $7.45 \pm 0.05$ & $7.47 \pm 0.06$ & $7.46 \pm 0.04$ & $7.40 \pm 0.05$ & $7.39 \pm 0.06 \dagger$ & $7.41 \pm 0.06$ \\
\hline $\mathrm{PCO}_{2}(\mathrm{mmHg})$ & $46 \pm 5$ & $45 \pm 9$ & $42 \pm 3$ & $38 \pm 4 \dagger$ & $45 \pm 4$ & $44 \pm 1$ & $44 \pm 5$ & $44 \pm 5$ & $44 \pm 4$ & $43 \pm 1$ & $46 \pm 3$ & $47 \pm 6$ \\
\hline Lactate $(\mathrm{mmol} / \mathrm{L})$ & $1.1 \pm 0.4$ & $2.2 \pm 0.9^{*}$ & $2.5 \pm 0.6^{*}$ & $4.5 \pm 0.7 *$ & $3.4 \pm 1.5^{*}$ & $3.3 \pm 1.2^{*}$ & $1.5 \pm .5$ & $1.9 \pm 0.7$ & $3.2 \pm 1.2 *$ & $6.5 \pm 1.7^{*}$ & $6.3 \pm 2.4 * \ddagger$ & $4.7 \pm 2.2 *$ \\
\hline $\mathrm{Po}_{2}(\mathrm{mmHg})$ & $366 \pm 134$ & $282 \pm 50$ & $264 \pm 58$ & $339 \pm 75$ & $238 \pm 55$ & $319 \pm 85$ & $333 \pm 131$ & $337 \pm 127$ & $315 \pm 120$ & $350 \pm 131$ & $269 \pm 149$ & $257 \pm 178 \dagger$ \\
\hline
\end{tabular}

$C P B$, Cardiopulmonary bypass; $B E$, arterial base excess; $p H$, arterial $\mathrm{pH} ;$ Lactate, arterial lactate level. $* P \leq .001$ relative to baseline, within group. $\dagger P \leq .05$ relative to baseline,

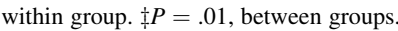

extremity cutdown. Electrocautery through skeletal muscle was performed during these procedures. Mean platelet levels decreased after the CPB run, but no significant difference between groups was identified.

\section{DISCUSSION}

This is the first report of ${ }^{15} \mathrm{O}$ PET scanning during CPB to evaluate $\mathrm{CBF}$ and $\mathrm{CMRO}_{2}$. In addition, the effects of HBOC-201 in the priming solution on hemodynamics, oxygen delivery and consumption, cerebral perfusion and oxygenation, and systemic inflammatory markers were evaluated. During CPB, the mean arterial pressure was slightly higher in the HBOC group, which is consistent with the known mild vasoconstrictive properties of the HBOC. This effect might be beneficial during CPB, when the use of vasoconstrictors to maintain an adequate perfusion pressure is often required. The need for lowdose inotropic support for a brief period after separation from CPB was unique to the HBOC group. The cause is not clear, but the requirement was transient. The only prior study evaluating $\mathrm{HBOC}-201$ during $\mathrm{CPB}^{21}$ was performed in a canine model, and the post-CPB left ventricular enddiastolic pressure and $\mathrm{dP} / \mathrm{dt}$ measurements were unchanged from baseline, suggesting left ventricular function was preserved. In our study the animals were not instrumented to determine these parameters. Visual inspection of myocardial function was also impaired because of positioning within the PET scanner. Pigs are prone to development of pulmonary hypertension in the perioperative period after CPB. The potential contribution of pulmonary vasoconstriction and hypertension cannot be evaluated in our study. Future studies should further investigate the cause underlying this transient need for inotropic/vasopressor support.
The mean hemoglobin concentration in the HBOC group was higher at baseline and throughout the study. The unexpectedly low mean baseline hemoglobin level in the pigs compared with the HBOC-201 formulation contributed to this difference. HBOC-201 is a $13 \mathrm{~g} / \mathrm{dL}$ solution (Table $5)$, and even though a similar volume of donor blood was used for priming the circuit in the non-HBOC group, the mean total hemoglobin level was consistently $1.5 \mathrm{~g} / \mathrm{dL}$ higher in the $\mathrm{HBOC}$ group. The mean $\mathrm{CaO}_{2}$ value is directly related to the total hemoglobin value and therefore was also higher in the HBOC group. The mean $\mathrm{Do}_{2}$ value was not significantly different between the groups but did decrease in a 1:1 relationship as the CPB flow was decreased. The mean $\mathrm{VO}_{2}$ value seemed to be slightly higher in the HBOC group, but this difference was not significant. The mean $\mathrm{VO}_{2}$ value was maintained at near baseline values at $75 \%$ flow by an increase in oxygen extraction in both groups. The mean mixed venous oxygen saturation value was also lower in the HBOC group but did not achieve statistical significance. Once CPB flow and the $\mathrm{Do}_{2}$ value were decreased to $50 \%$, the mean $\mathrm{VO}_{2}$ value decreased significantly from baseline, and mean mixed venous saturation was critically low in both groups. By maintaining the animals in a normothermic state and decreasing the flow rate, $\mathrm{VO}_{2}$ became dependent on $\mathrm{Do}_{2}$.

Mean methemoglobin levels were higher in the HBOC group, but with a peak level of $2.3 \% \pm 0.8 \%$, there is no clinical significance. The enzyme methemoglobin reductase is located within erythrocytes and therefore unable to act on hemoglobin outside the cell. In the blood group animals became mildly acidemic, with a higher peak lactate level and a slower decrease after normal flow was restored. Lactate is a product of cellular respiration during anaerobic metabolism. This pattern of lactate in the HBOC group

TABLE 4. Cerebral blood flow and oxygen use

\begin{tabular}{|c|c|c|c|c|c|c|c|c|}
\hline & \multicolumn{4}{|c|}{ HBOC-201 prime $(n=5)$} & \multicolumn{4}{|c|}{ Blood prime $(n=6)$} \\
\hline & $100 \%$ & $75 \%$ & $\mathbf{5 0} \%$ & $100 \%$ & $100 \%$ & $75 \%$ & $\mathbf{5 0} \%$ & $100 \%$ \\
\hline $\mathrm{CBF}(\mathrm{mL} / 100 \mathrm{~g} / \mathrm{min})$ & $51.4 \pm 8.3$ & $44.8 \pm 8.4$ & $33.8 \pm 10.7 \dagger$ & $63.4 \pm 11.6$ & $52.3 \pm 11.8$ & $53.0 \pm 13.8$ & $32.3 \pm 11.6^{*}$ & $68.3 \pm 11.5 \dagger$ \\
\hline $\mathrm{CMRO}_{2}(\mathrm{~mL} / 100 \mathrm{~g} / \mathrm{min})$ & $2.97 \pm 0.72$ & $2.85 \pm 0.51$ & $2.49 \pm 0.36$ & $3.1 \pm 0.52$ & $2.92 \pm 0.96$ & $3.17 \pm 0.71$ & $2.08 \pm 0.65 \ddagger$ & $3.22 \pm 0.76$ \\
\hline $\mathrm{OEF}$ & $0.46 \pm 0.14$ & $0.53 \pm 0.11$ & $0.61 \pm 0.17 \S$ & $0.43 \pm 0.11$ & $0.56 \pm 0.19$ & $0.57 \pm 0.15$ & $0.63 \pm 0.19$ & $0.46 \pm 0.13$ \\
\hline
\end{tabular}

$\overline{C B F}$, Cerebral blood flow; $\mathrm{CMRO}_{2}$, cerebral metabolic rate of oxygen; $\mathrm{OEF}$, cerebral oxygen extraction fraction. $* P=.004$ relative to initial full flow (100\%), within group. $\dagger P=.02$ relative to initial full flow $(100 \%)$, within group. $\ddagger P=.01$ relative to initial full flow $(100 \%)$, within group. $\S P=.05$ relative to initial full flow (100\%), within group. 
TABLE 5. Inflammatory markers and cardiac enzymes

\begin{tabular}{|c|c|c|c|c|c|c|c|}
\hline & \multicolumn{3}{|c|}{ HBOC-201 prime } & \multicolumn{3}{|c|}{ Blood prime } & \multirow[b]{2}{*}{$P$ value, between groups } \\
\hline & Baseline & Completion & $P$ value, within group & Baseline & Completion & $P$ value, within group & \\
\hline Total CK & $928 \pm 528$ & $3414 \pm 3104$ & .001 & $589 \pm 160$ & $1653 \pm 602$ & $<.001$ & NS \\
\hline CK-MB & $10 \pm 9$ & $289 \pm 348$ & .02 & $5 \pm 7$ & $125 \pm 290$ & .08 & .05 \\
\hline Troponin I & $0.1 \pm 0.1$ & $9.8 \pm 3.8$ & $<.001$ & $0.1 \pm 0.1$ & $4.6 \pm 1.6$ & $<.001$ & .08 \\
\hline AST & $47 \pm 9$ & $252 \pm 182$ & $<.001$ & $41 \pm 12$ & $144 \pm 70$ & $<.001$ & NS \\
\hline BUN & $8 \pm 3$ & $13 \pm 3$ & $<.001$ & $10 \pm 4$ & $16 \pm 5$ & $<.001$ & NS \\
\hline Magnesium & $2.0 \pm 0.5$ & $2.2 \pm 0.5$ & NS & $1.8 \pm 0.2$ & $2.4 \pm 0.2$ & .003 & NS \\
\hline Platelets & $313 \pm 132$ & $198 \pm 52$ & .05 & $333 \pm 151$ & $184 \pm 33$ & .004 & NS \\
\hline IL-6 & $101 \pm 78$ & $587 \pm 765$ & .02 & $46 \pm 59$ & $158 \pm 87$ & .09 & .07 \\
\hline TNF- $\alpha$ & $235 \pm 187$ & $253 \pm 45$ & NS & $138 \pm 54$ & $166 \pm 78$ & NS & NS \\
\hline
\end{tabular}

$C K$, Creatine kinase; $C K-M B$, creatine kinase $\mathrm{MB} ; A S T$, aspartate aminotransferase; $B U N$, blood urea nitrogen; $I L-6$, interleukin 6 ; $T N F$ - $\alpha$, tumor necrosis factor $\alpha$.

suggests less anaerobic metabolism and more rapid clearance. This finding supports our hypothesis that during the low-flow state, improved oxygen unloading and tissue use leads to less anaerobic metabolism.

Mean CBF was not significantly different between the 2 groups, and autoregulation prevented a significant decrease in mean CBF until the CPB flow was decreased to $50 \%$. When flow was restored to $100 \mathrm{~mL} \cdot \mathrm{kg}^{-1} \cdot \mathrm{min}^{-1}$, an increase in mean CBF was seen in both groups and has been described as reactive hyperemia after an ischemic insult. Similarly, at $75 \%$ flow, $\mathrm{CMRO}_{2}$ was no different than full flow. When the flow was further reduced to $50 \%$, only the value in the blood group decreased significantly. The mean $\mathrm{CMRO}_{2}$ value in the $\mathrm{HBOC}$ group decreased by $16 \%$, whereas that in the blood group decreased $29 \%$ relative to full flow. Once flow was restored, the mean oxygen metabolism returned to normal. These data further support the hypothesis that using HBOC-201 as an oxygen therapeutic during $\mathrm{CPB}$ can maintain $\mathrm{CMRO}_{2}$ during low-flow states by facilitating efficient oxygen use.

Levels of a number of the ischemia and inflammatory markers increased significantly on average from baseline to after CPB. This pattern was seen in total CK, CK-MB, troponin I, aspartate aminotransferase, and interleukin 6 levels. In all of these, the mean increase was greater in the HBOC group. The difference between values at completion was only significantly higher in the HBOC group for CK-MB, although the difference in troponin levels approached significance $(P=.08)$. Interestingly, mean TNF- $\alpha$ levels did not increase significantly during the experiment, and there was no significant difference between groups. The cause for these findings is unclear. Global mean oxygen delivery was similar for both groups, and mean oxygen use was slightly higher in the HBOC group. Histopathology was not performed in this study. Previous studies found an increase in liver function test results after HBOC treatment without evidence of significant injury. ${ }^{7}$ The increased troponin level seen with HBOC has been previously reported in a canine model using crystalloid cardioplegia. ${ }^{22}$ In that study the magnitude of increase was much higher because of the global myocardial ischemia induced by aortic crossclamp application but followed a similar pattern. However, other models have found a myocardial protective effect of HBOC. In a canine model of experimental myocardial ischemia $^{14}$ using HBOC-201 as pretreatment, infarct size was smaller and cardiac enzyme increase was significantly less in the treatment group. In a rabbit model of coronary occlusion, ${ }^{13}$ both prophylactic and therapeutic administration of HBOC decreased the size of the myocardial infarction without reducing the area of impaired perfusion. Increased troponin levels after HBOC treatment continue to be a concern, but the clinical effect of the mild increase in our study requires further evaluation.

Our study has several limitations. First, the difference in mean hemoglobin levels confounds the interpretation of the oxygen delivery and consumption data. Although the mean $\mathrm{Do}_{2}$ value was not significantly different between the groups, the following question arises: Was the improved performance in the HBOC group the result of the HBOC's properties or of the higher mean total hemoglobin level?

Although this is a weakness of our research study, it is exactly how we expect this product would be used clinically. When adding HBOC-201 to the bypass circuit, the circulating free hemoglobin would capitalize on the unique properties in the intraoperative and immediate postoperative periods, when end-organ malperfusion is most likely. The cell-free hemoglobin would be in addition to the red blood cell hemoglobin and not a substitute for transfusion.

Second, using a healthy juvenile animal to evaluate endorgan perfusion as a model for human patients with diffuse atherosclerosis is imperfect. Situations in which the mechanism of decreased oxygen delivery is due to vascular occlusive disease rather than low CPB flow rates might behave differently than our model.

Finally, the nonsurvival model does not allow for correlation of the immediate intraoperative findings to functional neurologic outcomes. Future investigations should use a survival model to evaluate the postoperative neurologic status and confirm that increased mean $\mathrm{CMRO}_{2}$ levels during $\mathrm{CPB}$ lead to better clinical outcomes. 


\section{CONCLUSIONS}

In our porcine model addition of HBOC-201 to the pump-priming solution during CPB improves cerebral oxygenation and decreases overall tissue ischemia compared with priming with donor whole blood. Further evaluation of immediate post-CPB myocardial function and increased cardiac enzyme levels after exposure to HBOC-201 should be performed before clinical application. The unique oxygen-unloading properties have the potential to improve tissue oxygenation in numerous conditions of decreased oxygen delivery.

HBOC-201 was provided free of charge by Biopure Corporation (Cambridge, Mass). Technical support was provided by the 59th Clinical Research Squadron, Wilford Hall Medical Center, and the Laboratory Animal Resources and Research Imaging Center at the University of Texas Health Science Center, San Antonio, Texas. Assistance with statistical analysis was provided by Prakash Nair, PhD, Department of Epidemiology and Biostatistics, University of Texas Health Science Center, San Antonio, Texas.

\section{References}

1. Bucci E. Thermodynamic approach to oxygen deliver in vivo by natural and artificial oxygen carriers. Biophys Chem. 2009;142:1-6.

2. Koehler RC, Fronticelli C, Bucci E. Insensitivity of cerebral oxygen transport to oxygen affinity of hemoglobin-based oxygen carriers. Biochim Biophys Acta. 2008;1784:1387-94.

3. Tsoukias NM, Goldman D, Vadapalli A, Pittman RN, Popel AS. A computational model of oxygen delivery by hemoglobin-based oxygen carriers in threedimensional microvascular networks. J Theor Biol. 2007;248:657-74.

4. Dimino ML, Palmer AF. Hemoglobin-based $\mathrm{O}_{2}$ carrier $\mathrm{O}_{2}$ affinity and capillary inlet $\mathrm{pO}_{2}$ are important factors that influence $\mathrm{O}_{2}$ transport in a capillary. Biotechnol Prog. 2007;23:921-31.

5. Kavdia M, Pittman RN, Popel AS. Theoretical analysis of effects of blood substitute affinity and cooperativity on organ oxygen transport. J Appl Physiol. 2002; 93:2122-8.

6. McNeil JD, Smith DL, Jenkins DH, York GB, Josephs JJ. Hypotensive resuscitation using a polymerized bovine hemoglobin-based oxygen-carrying solution (HBOC-201) leads to reversal of anaerobic metabolism. J Trauma. 2001;50: 1063-75.

7. York GB, Eggers JS, Smith DL, Jenkins DH, McNeil JD, Mueller D, et al. Lowvolume resuscitation with a polymerized bovine hemoglobin-based oxygen- carrying solution (HBOC-201) provides adequate tissue oxygenation for surviva in a porcine model of controlled hemorrhage. $J$ Trauma. 2003;55:873-85.

8. Sampson JB, Davis MR, Mueller DL, Kashyap VS, Jenkins DH, Kerby JD. A comparison of the hemoglobin-based oxygen carrier HBOC-201 to other low-volume resuscitation fluids in a model of controlled hemorrhagic shock. J Trauma. 2003;55:747-54.

9. Fitzpatrick CM, Biggs KL, Atkins BZ, Quance-Fitch FJ, Dixon PS, Savage SA, et al. Prolonged low-volume resuscitation with HBOC-201 in a large-animal survival model of controlled hemorrhage. J Trauma. 2005;59:273-83.

10. Frackowiak RSJ, Lenzi GL, Jones T, Heather JD. Quantitative measure of regional cerebral blood flow and oxygen metabolism in man using ${ }^{15} \mathrm{O}$ and positron emission tomography: theory, procedure, and normal values. J Comput Assist Tomogr. 1980;4:727-36.

11. Poulsen PH, Smith DF, Ostergaard L, Danielsen EH, Gee A, Hansen SB, et al. In vivo estimation of cerebral blood flow, oxygen consumption and glucose metabolism in the pig by ${ }^{15} \mathrm{O}$ water injection, ${ }^{15} \mathrm{O}$ oxygen inhalation and dual injections of ${ }^{18} \mathrm{~F}$ fluorodeoxyglucose. J Neurosci Methods. 1997;77:199-209.

12. Mortberg E, Cumming P, Wiklund L, Rubertsson S. Cerebral metabolic rate of oxygen $\left(\mathrm{CMRO}_{2}\right)$ in pig brain determine by PET after resuscitation from cardiac arrest. Resuscitation. 2009;80:701-6.

13. Rempf C, Standl T, Schenke K, Chammas K, Gottschalk A, Burmeister MA, et al Administration of bovine polymerized haemogloving before and during coronary occlusion reduces infarct size in rabbits. Br J Anaesth. 2009;103:496-504.

14. Caswell JE, Strange MB, Ribber DM, Gibson MF, Cole P, Leffer DJ. A novel hemoglobin-based blood substitute protects against myocardial reperfusion injury. Am J Physiol Heart Circ Physiol. 2005;288:H1796-801.

15. King DR, Cohn SM, Proctor KG. Resuscitation with a hemoglobin-based oxygen carrier after traumatic brain injury. J Trauma. 2005;59:553-62.

16. Patel MB, Feinstein AJ, Saenz AD, Majetschak M, Proctor KG. Prehospital HBOC-201 after traumatic brain injury and hemorrhagic shock in swine. J Trauma. 2006;61:46-56.

17. Freitag M, Standl TG, Gottschalk A, Burmeister MA, Rempf C, Horn EP, et al Enhanced central organ oxygenation after application of bovine cell-free hemoglobin HBOC-201. Can J Anesth. 2005;52:904-14.

18. National Research Council. Guide for the care and use of laboratory animals. Washington, DC: National Academy Press; 1996.

19. Lee K, Fox PT, Lancaster JL, Jerabek PA. A positron-probe system for arterial input function quantification for positron emission tomography in humans. Rev Sci Instrum. 2008;79:064301.

20. Ohta S, Meyer E, Fujita H, Reutens DC, Evans A, Gjedde A. Cerebral ${ }^{15} \mathrm{O}$ water clearance in humans determined by PET: I. Theory and normal values. $J$ Cereb Blood Flow Metab. 1996;16:765-80.

21. Neragi-Miandoab S, Guerrero JL, Vlahakes GJ. Autologous blood sequestration using a double venous reservoir bypass circuit and polymerized hemoglobin prime. ASAIO J. 2002;48:407-11.

22. Neragi-Miandoab S, Vlahakes GJ. Elevated troponin I level with hemoglobin based oxygen carrying solutions (HBOC) as a priming solution despite improved left ventricular function. Interact Cardiovasc Thorac Surg. 2006;5: 135-8. 